\title{
Research on financial supervision in Northeast Asia Free Trade Zone - Based on the "Regulatory Sandbox" model
}

\author{
Qian $\mathrm{Li}^{1{ }^{1}{ }^{*}, \text { Juying } \mathrm{Xi}^{1} \text {, Chuang Zhang }}{ }^{1}$, and Yue Zheng ${ }^{1}$ \\ ${ }^{1}$ School of Economics, Shenyang University of Technology, China
}

\begin{abstract}
This paper analyzes the status quo of financial supervision in the Northeast Asia Free Trade Zone and finds that the coordination and cooperation of financial supervision in the Northeast Asia Free Trade Zone is in the exploratory stage. There is room for cooperation in financial supervision, which creates conditions for the implementation of the "supervisory sandbox" in the region. It demonstrates the significance of introducing the "regulatory sandbox" model in the Northeast Asia Free Trade Zone from three aspects: balancing financial innovation and supervision, promoting the realization of inclusive finance, and improving the global shared supervision database. Build a relatively complete "supervision sandbox" operation process design. Finally, the countermeasures and suggestions for the introduction of the "supervisory sandbox" model in the Northeast Asia Free Trade Zone are proposed.
\end{abstract}

\section{Analysis on the current situation of financial supervision in Northeast Asia Free Trade Zone}

The framework of China's current financial supervision mode is "one committee, one bank and two sessions", it represents the financial stability and Development Commission of the State Council, the central bank, the Securities Regulatory Commission and the banking and Insurance Regulatory Commission. Under the new supervision mode, the functions of the central bank not only maintain the original formulation which includes macro-control and monetary policy, but also increase the formulation of important laws and regulations and prudential supervision system of banking and insurance industry, that is to say, it takes on the burden of preventing systemic risks.

Japan adopts the unified supervision mode. This is due to the fact that banks and enterprises are closely related in Japanese financial industry and most of them belong to the same chaebol and the government intervenes a lot. Japan sets up a financial supervision agency to supervise all financial institutions. The Tibetan province retains the function of formulating financial policies. The central bank mainly carries out risk identification and monitoring, and allows mixed operation through the establishment of financial holding companies. Korea adopts the unified supervision mode. Its current financial supervision

\footnotetext{
* Corresponding author: 409861577@qq.com
} 
system is mainly composed of financial committee, financial supervision institute, Korean bank and deposit insurance company.

The coordination and cooperation in financial supervision of Northeast Asia free trade zone is in the exploratory stage. The modes and mechanisms of cooperation can be divided into two types: bilateral level and regional multilateral level. It is the main form of bilateral cooperation that financial regulators sign the memorandum of understanding on financial supervision. At present, China's regulators have signed memoranda of understanding on bilateral regulatory cooperation with Japan, South Korea, Mongolia and Russia respectively. Through the signing of memorandum of understanding, we can cooperate in information exchange, market access and on-site inspection, personnel exchange and training which is in order to improve the ability of cross-border supervision. The regional multilateral regulatory cooperation mechanism of Northeast Asia free trade zone is more macroscopic. At the 9th China Japan South Korea high level meeting of regulators, all parties discussed in-depth the regulatory cooperation in the financial industry. At the meeting, the South Korean government's innovation and development strategy, financial science and technology policy, and the degree of openness of China's financial market were delivered, and an agreement was reached on deepening policy cooperation in the future. In the future, it will deepen the supervision coordination and cooperation of Northeast Asia Free Trade Zone, and the realization of this process can not be separated from the innovation of financial supervision of various countries.

\section{The significance of introducing financial "supervision sandbox" mechanism}

The innovation of financial science and technology can promote the sustainable development of economy, and the innovation of financial technology has become an irreversible trend. The following problem is how to supervise the innovation of financial science and technology. It is in this context that the "regulatory sandbox" came into being. "Sandbox" is also called "sandbox", a kind of virtual technology and widely used in the field of computer security. The concept of "regulatory sandbox" was first put forward by the United Kingdom, followed by the attention and recognition of various countries, and has been adopted and innovated in varying degrees.

\subsection{Balancing financial innovation and regulation}

The proposal of "regulatory sandbox" can effectively improve the regulatory information asymmetry among regulators, financial technology enterprises and consumers, better balance the difficult problems of financial innovation and financial supervision, and properly solve the dynamic balance between risk prevention and innovation promotion. The proposal of regulatory sandbox gives those start-up technology enterprises and financial institutions to test new financial models, new business processes and new financial products by lowering the entry threshold and relaxing regulatory restrictions within a specific time and scope. In this way, there will be two paths for the tested patterns, products and other projects in the future. One is projects that pass the test, the regulatory authorities can approve the relevant application agencies, so that these projects can be more widely used in life, regardless of whether these projects fully comply with the existing laws and regulations. The other is projects that fail to pass the test, which may not achieve the expected effect or have adverse effects on the existing system, and the regulatory authorities will terminate the continuation of these projects. 


\subsection{Promoting the realization of inclusive finance}

The implementation of "regulatory sandbox" helps to solve the problem of Inclusive Finance. There is a coupling mechanism between Inclusive Finance and regulatory sandbox. This is because the implementation of the "regulatory sandbox" can expand the audience range of financial services and products, and consumers can enjoy the financial services and products that have been tested successfully by the "regulatory sandbox", which makes the users of the financial market expand to the periphery. However this may not be realized under the original regulatory system. "Regulatory sandbox" actively opens up space for inclusive finance through innovation. In formulating the sandbox standard, inclusive financial indicators can be added to the sandbox operation mechanism. The regulators can also provide continuous support to create a favorable environment for innovative products such as digital finance, and facilitate regulators to measure the path of financial technology in the mechanism of Inclusive Finance, so as to enhance the targeting, expand the breadth and depth of financial services, and then contribute to shorten the gap between urban and rural financial services.

\subsection{Help to improve the global shared regulatory database}

Join the international regulatory sandbox alliance and contribute to the construction of a more extensive shared regulatory database worldwide. The Global Financial Innovation Alliance (GFIN) initiative initiated by FCA shares the implementation experience of regulatory sandbox, promotes the improvement and construction of integrity finance, Inclusive Finance and consumer protection, which helps to broaden the perspective of global regulation.

\section{Design of the operation process of the "Supervision Sandbox" in the Northeast Asia Free Trade Zone}

The specific assumptions of the "regulatory sandbox" model in the Northeast Asia Free Trade Zone are now explained. Clarify the scope of applicants. To have a clear conclusion on this issue, two uncertainties must be resolved first. As we all know, the most important significance of introducing the "regulatory sandbox" model is to solve the problem of financial innovation and regulatory risk prevention. It is necessary to know exactly which are the subjects of financial innovation, to clarify the scope of financial technology innovation. It should include banks, securities companies and other financial institutions, technological innovation companies, and companies that can provide technical support or services to the above-mentioned companies. On the other hand, what needs to be made clear is the establishment of a regulatory agency with a "regulatory sandbox" model. Whether it is the United Kingdom, Australia or Singapore, there are special financial behavior supervision agencies, but our country is still lacking in this aspect. The solution can be to establish a local financial behavior supervision office, linked to the local central bank.

After clarifying the above two aspects, the scope of the applicant can now be determined. All subjects of financial innovation should be eligible to apply. Especially those powerful start-ups and small related companies should actively participate. It should also be noted that the joint research and development of innovative products or services by different companies should also be included in the sandbox model.

Clarify the requirements for the applicant to submit the project. Generally, the following three aspects should be satisfied. One is that the project applied for must have substantial innovation, which can be efficiency improvement, cost reduction, and experience 
satisfaction enhancement. The second is to have a complete consumer protection mechanism. The applicant organization should clarify the consumer' s right to know, property security, and claim for compensation. The third is sound risk management measures. The applicant organization should prepare a plan for possible undesirable problems to ensure that they can be dealt with quickly when they occur, so as to minimize the losses of all parties. For emergencies, experts in related fields can also be quickly organized to discuss and negotiate solutions in time to reduce risks.

After the applicant organization is approved by the regulatory agency, it enters the sandbox testing stage. Combined with the analysis of my country's localization situation, the sandbox testing stage of the Northeast Asia Free Trade Zone pays attention to the testing time, supervision and restriction conditions. Attention should be paid to two aspects of supervision issues in the testing phase. One is that the competent regulatory agency should send officials to the applicant organization to supervise and guide; the other is that the regulatory agency should perform full supervision during the sandbox test, so that the regulatory agency can deepen the financial innovation in real time. Understanding and adjustment. Restrictions during the test period must be strictly observed, such as within the approved time limit, test scale, and limited number of consumers.

After the testing phase is over, it comes to the sandbox exit problem. There are two paths for applicants to choose. One is to directly exit the "regulatory sandbox" model and no longer provide related products or services to the society; the other is to apply for a license from the regulatory agency to become a project that fully complies with the regulatory rules and regulations. If the regulatory agency approves the application, the project can be promoted to the entire free trade zone and the whole society; if the regulatory agency rejects the application, the project cannot serve the financial market temporarily.

Applicants participating in the sandbox test need to submit a complete report of the project within 2 months of the end of the sandbox test. Based on the report, the regulatory agency will form a final regulatory report, so that when encountering similar financial innovation projects in the future, they can learn from material.

The "regulatory sandbox" model of the free trade zone should be divided into four stages, namely application entry, sandbox testing, sandbox exit, and project reporting. The flow chart of the envisaged "regulatory sandbox" model is shown in Figure 1.

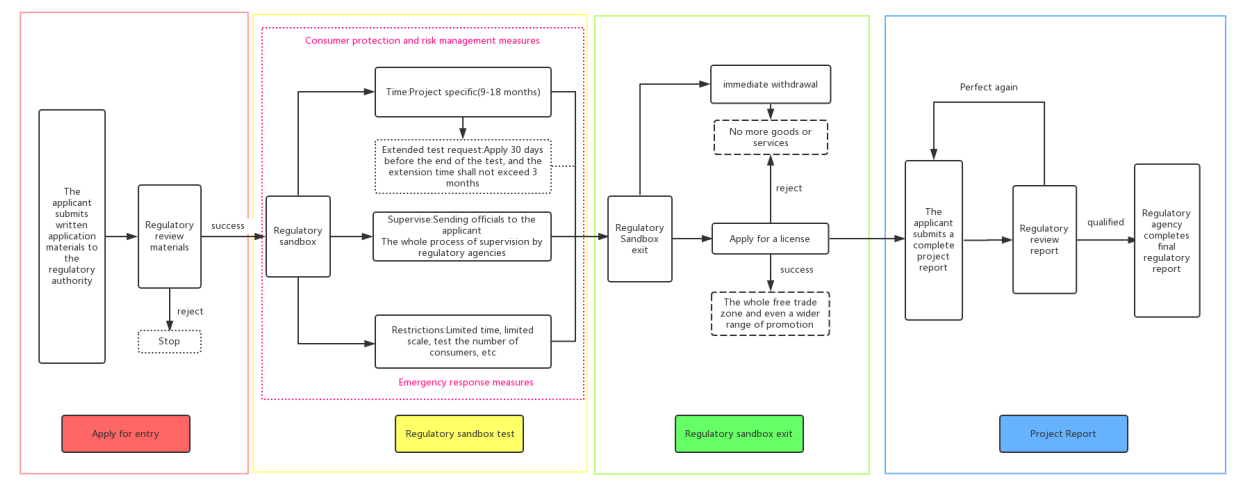

Fig. 1. The envisaged flow chart of the "regulatory sandbox" model of the Northeast Asia Free Trade Zone. 


\section{Suggestions for the introduction of the "Supervision Sandbox" model in the Northeast Asia Free Trade Zone}

\subsection{Coordinating the "regulatory sandbox" model of countries in the Northeast Asia Free Trade Zone}

The Northeast Asia Free Trade Zone spans six countries. The introduction of a sandbox mechanism in the Northeast Asia Free Trade Zone requires that countries reach an agreement to form a "regulatory sandbox" model in the free trade zone. This is for the regulatory innovation model that has just started. is very difficult. Therefore, the countermeasure suggestion to introduce the sandbox mechanism in the free trade zone is to first establish a "regulatory sandbox" model in each country, and then after this "regulatory sandbox" model operates for a period of time, each country will unify it. Explore the "regulatory sandbox" model that is in line with the Northeast Asia Free Trade Zone. This model is mainly the evolution or extension of the common points and similarities in each country's own models. Call on other countries in the Northeast Asia Free Trade Zone to explore the "regulatory sandbox" model, and can strictly control the specific establishment of companies and implement their own "regulatory sandbox" model as soon as possible. Then explore in the Northeast Asia Free Trade Zone, sort out a "regulatory sandbox" model that is in line with each country, and finally achieve a win-win situation for all countries in the Northeast Asia Free Trade Zone, and even promote the surrounding areas of the Northeast Asia Free Trade Zone. development of.

\subsection{Enhancing technological and financial strength in the free trade zone}

The Northeast Asia Free Trade Zone mainly includes the Northeast of my country. The scientific and technological strength and financial strength of the Northeast region are still far behind some places in the central and eastern parts of my country. The countermeasure suggestion for introducing the sandbox mechanism in the free trade zone is to vigorously develop scientific and technological strength and financial strength in the Northeast region, combine its own characteristics, build high-tech industrial parks in line with the Northeast region, make full use of its own advantages, and introduce corresponding technologies and related aspects. Talents, create a great development space for technology and other related talents, attach importance to cultivating talents' innovation and shaping ability, and strive to provide a more solid technology and financial environment for China in the Northeast Asia Free Trade Zone.

\section{References}

1. Zhang X Y, Zhao Y. Supply-side deleveraging risk and development path research [J]. Contemporary Economic Management, 2018, 40(07): 16-21.

2. Yu J P. On the new opportunities provided by China-EU financial cooperation for both China and Europe[J]. Economic Forum, 2009(21):17-19.

3. Zhang J Z. The international model of "regulatory sandbox" and the development path of Mainland China[J]. Financial Supervision Research, 2017(05): 22-35.

4. Liu Z Y, Liu S. The innovation of financial technology legal regulation-the development trend and localization thinking of the regulatory sandbox[J]. Journal of Xiamen University (Philosophy and Social Sciences Edition), 2019(02): 21-31. 